\title{
Economic factors that determine the quantity and Characteristics of Solid Waste in Bauchi Metropolis, Nigeria
}

\author{
Bogoro A. G., Bukar A. G., Samson M. N., and Rasheed O. \\ Abubakar Tafawa Balewa University, Bauchi, Nigeria
}

\begin{abstract}
The rapid growth of urbanisation due to industrialisation has brought astronomical increase in anthropogenic activities with their attendant huge generation of wastes, thus the need for a systematic management of an ever-increasing trend of municipal solid waste generation complicated by complex waste characteristics has become an urban challenge The research is carried out to determine the implication of economic variable (income) on the composition and quantity of solid waste generation in Bauchi metropolis. Systematic random sampling technique was adopted for the selection of the samples and $4 \%$ of the study population was taken as the sample size. The major instruments used for data collection were questionnaire, interview and direct measurement of household solid waste at source and the data is presented in tables and charts. The spearman rank correlation was used for statistical analysis to determine the degree of relationship between income level and quantity of solid waste generation. The result of hypothesis shows that the calculated value of $r=0.871$. This indicates that there is high positive correlation between the two variables, that shows that the quantity and composition of solid waste generation is influenced by level of economic development It is recommended that the roles of income in determining the quantity and composition of solid waste, are to be identified and integrated in the solid waste management strategies with a view to achieving a clean and healthy living environment in Bauchi metropolis
\end{abstract}

Key words: income, solid waste, composition, quantity

\section{Introduction}

Current global Municipal Solid Waste (MSW) generation levels are approximately 1.3 billion tonnes per year, and are expected to increase to approximately 2.2 billion tonnes per year by 2025 . This represents a significant increase in per capita waste generation rates, from 1.2 to $1.42 \mathrm{~kg}$ per person per day in the next fifteen years, World Bank (2012). However, global averages are broad estimates only as rates vary considerably by region, country, city, and even within cities. MSW generation rates are influenced by economic development, the degree of industrialization, public habits, and local climate, UN Habitat, (2006). Generally, the higher the economic development and rate of urbanization, the greater the amount of solid waste produced. Income level and urbanization are highly correlated and as disposable incomes and living standards increase, consumption of goods and services correspondingly increases, as does the amount of waste generated. Urban residents produce about twice as much waste as their rural counterparts, Miller, (1999) and Miranda, (1994). The quantity and composition of solid waste generated directly reflects on the prevailing socio-economic and physical status of the society Abel, (2009). Urbanisation, consumption pattern, occupation and income level, technology, legislation and geographical and physical factors are all crucial in determining the amount of waste generation. In ancient times, solid waste was not a problem because it was mainly organic and small in quantity, there were only three ways to handle solid waste; throw it away, re-use it or do not generate it at all, but in recent times, due to changes in quantity and characteristics of the solid waste, the management of the solid waste has become a major urban challenges. Farming communities in centuries had practically no waste at all, as leftover food and bones were eaten up by the household animals, paper and wood was used for fire and even the ash end up on the manure pile to be used as fertilizer. Medina, (2005)

Researchers, Repettor et al (1992) have revealed that income level of a society determines the type of its solid waste. Its assumed that the higher a country's level of industrialization the higher its income level and the larger its proportion of toxic, non-organic and non-biodegradable solid waste, particularly packaging materials, paper, plastics, glass, and metal as in the table below:

Table 1 Solid Waste Composition (\%) For Selected Cities

\begin{tabular}{lllllll}
\hline Type of waste & UK & India & Japan & Kathmandu & China & Nigeria \\
& London & Delhi & Tokyo & Nepal & Wuhan & \begin{tabular}{l} 
Ibadan \\
\hline Vegetables
\end{tabular} \\
Rubbish & 18 & 49 & 28 & 67 & 17 & 32 \\
Plastic/leather & 7 & 38 & 31 & 10 & 78 & 47 \\
Textile & 3 & 1 & 11 & 0.5 & 0.5 & 12 \\
Glass & 10 & 1 & 10 & 7 & 0.5 & 07 \\
\hline
\end{tabular}


Economic factors that determine the quantity and Characteristics of Solid Waste in .....

\begin{tabular}{cllllll}
\hline Metals & 8 & 1 & 10 & 5 & 0.5 & 02 \\
Paper & 29 & 7 & 1 & 7 & 2 & 10 \\
Wood & n.a & n a & 2 & 3 & 2 & 4 \\
\cline { 2 - 9 }
\end{tabular}

Source: World Bank 2012

As cities began to grow due to industrialization and population densities increased, the composition of the solid waste changes towards inorganic stream. In United States, by the middle of $20^{\text {th }}$ century a drastic change had occurred in both the life style of the population and the composition of its refuse, UNHCS, (2003). The most noticeable change was the increase in the amount of plastics discarded. In 1960s to 1970, the concentration of plastics was between 1\% and 3\% in New York in 1980s, about 5\% of the solid waste consisted of plastics and 1986 the concentration of plastics reached 6.5\%. A similar trend was noted in Rome. Between 1962 and 1985, the concentration of kitchen waste, ash and dirt decreased while the amount of paper and glass nearly double and the concentration of plastic have risen from $0 \%$ in 1962 to $3 \%$ in 1985, Reschovsky et al, (1994)

Globally, the pattern of consumption decides the amount of goods each person uses. Consumption of goods rises as income rises, and so do waste generation. Those in want, waste least, World Bank, (2012). In poor countries, typical town dweller generates only 0.5 kilos of solid waste per person per day. In middle income countries, they produce about $0.7 \mathrm{kilos}$. In the late $1980 \mathrm{~s}$, the daily production of solid waste in high-income countries ranged from a low of 0.92kilos per person per day in Western Europe right up to 2.4kilos in America, the most wasteful nation on earth as in figure below.

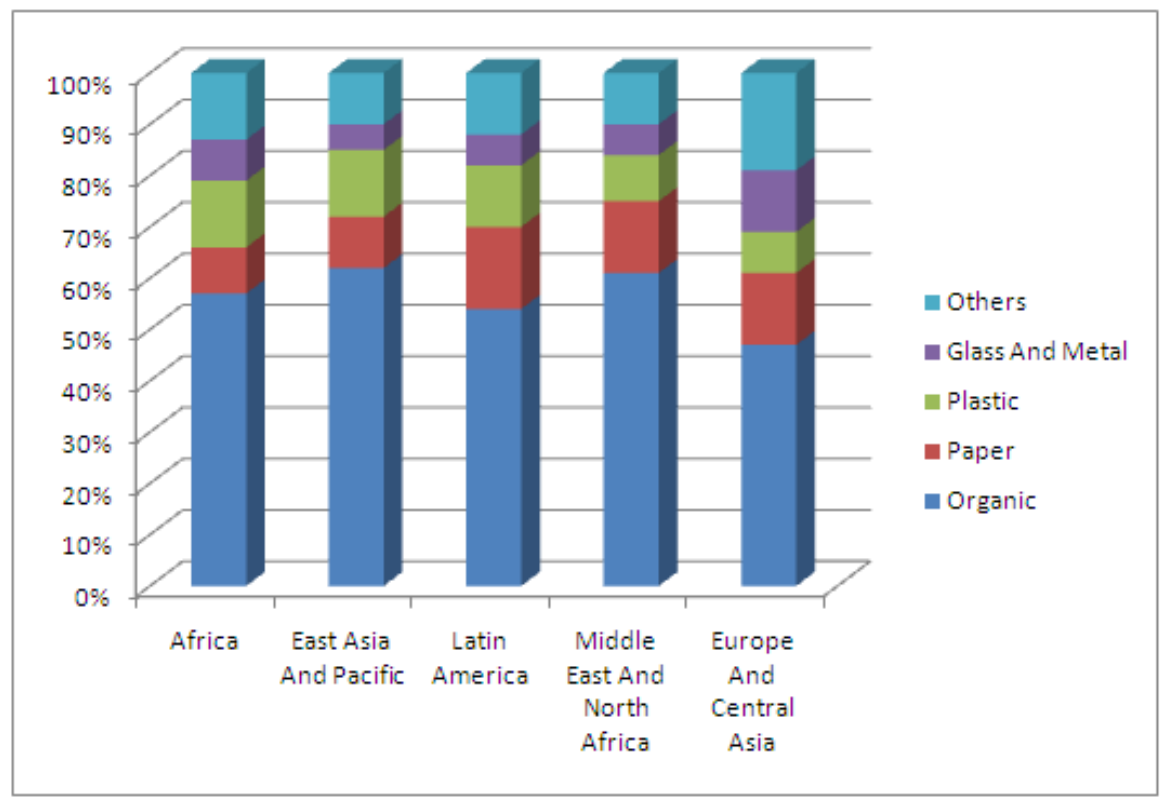

Figure 1 Global Characteristics of Waste Generation by Region. Source; World Bank, 2012

In Nigeria, the composition and quantity of solid waste generation is also a function of economic status, the solid waste in most of the urban centers that are of lower income level was dominated by vegetable perusable, while urban areas with high income like Lagos and Kano the solid waste are predominantly inorganic in nature as in the table below:

Table 2 Characteristics of Solid Waste in Some Nigerian Cities

\begin{tabular}{|l|c|c|c|c|c|c|c|}
\hline & Nsukka & Lagos & Makurdi & Kano & Bauchi & Onitsha & Maiduguri \\
\hline Rubbish & 56.0 & 44.2 & 52.2 & 43.0 & 50.4 & 40.7 & 25.8 \\
\hline Plastics & 8.4 & 4.0 & 8.2 & 4.6 & 3.3 & 9.2 & 18.1 \\
\hline Paper & 8.8 & 14.6 & 12.3 & 17.2 & 5.5 & 13.1 & 7.5 \\
\hline Textile & 3.1 & 10.6 & 2.5 & 7.7 & 6.0 & 6.2 & 3.9 \\
\hline Metal & 6.8 & 4.3 & 7.1 & 5.9 & 4.1 & 6.2 & 9.1 \\
\hline Glass & 2.5 & 3.3 & 3.6 & 2.1 & 2.0 & 9.2 & 4.3 \\
\hline Others & 14.4 & 19.0 & 14.1 & 19.5 & 28.7 & 15.4 & 31.3 \\
\hline
\end{tabular}

Sources; Ogwueleka (2003), Agunwamba et al (1998), Cointreau (1982), Dauda and Osita (2003) Bogoro (2013) 


\section{Methods And Materials}

Bauchi metropolis, the headquarters of Bauchi meropolis, is located between latitudes 9" 00 ' and 9" 30 ' North of the Equator and longitudes 10" 25 and 11" 20' East of the Greenwich Meridian It occupies a total land area of 3,604.0 hecteres. It has a total population of 318,038_people as at June 2010, population census NPC, (2006). Furthermore, based on the average household size of 8 persons per household as revealed by the 2006 census there are 39,675 households in the metropolis. For the purpose of sampling, the study area is divided into twelve wards (Gunduma) which form the sample frame. From each ward a proportionate unit of household will be selected for the purpose of administering questionnaire and interview. $4 \%$ of 39,675 households were taken as the sample size which is 1587 households For a heterogeneous environment like Bauchi metropolis, where social values and economic status, which to a great extent determined the quantity of solid generation and characteristics, are quite varied, stratified and systematic random sampling techniques was adopted for the selection of the samples. The instruments used in data collection includes; structured Questionnaire, oral Interview, direct measurement of solid waste on site, Observation, Photograph and Discussion

After the field survey, information obtained from questionnaires, interview guide and observation guide were collated and coded in a summary sheet. The data were further presented in tabular form in frequency distribution tables and percentages. Pie chart and bar charts were used for graphical description, comparison and assessment of the existing condition of refuse evacuation in the area. Photographs of solid waste collection centres were also taken to reveal the existing situation on ground.

\section{Result And Discussion}

Projected from 2006 census, the population of Bauchi metropolis stood at 318038 in June 2010, using the National growth rate for urban centers, which is $4.5 \%$. The survey revealed that female dominated with $50.6 \%$ (160 972) of the total population. The research reveals that $45.7 \%$ of the household heads in Bauchi metropolis are civil servants while up to $20.1 \%$ are farmers. The proportion of unemployed is as high as $7.0 \%$ as in the figure below

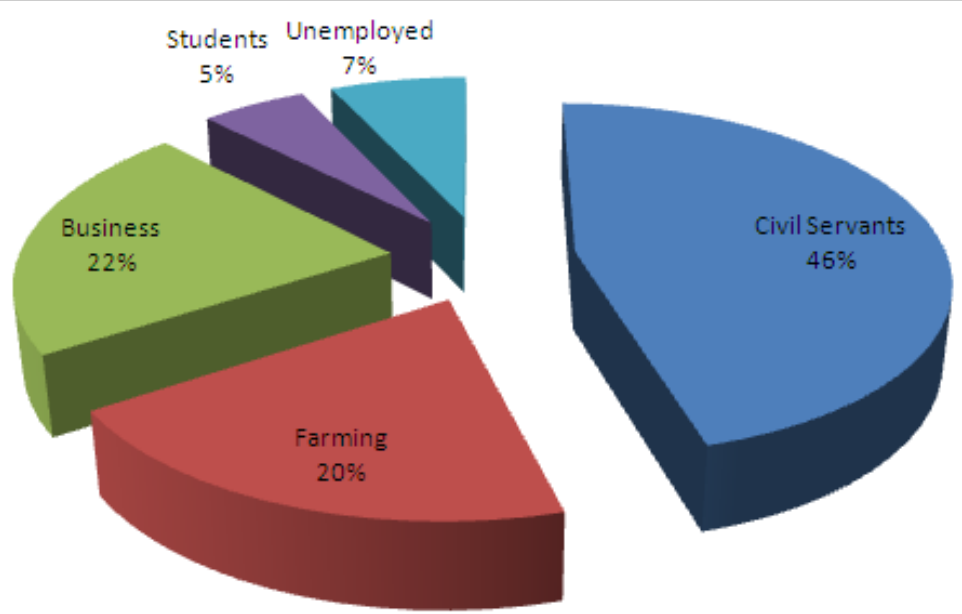

Figure 2 Occupation of Bauchi Metropolis

Unemployment and students constitute only $12.4 \%$, the remaining are engage in one occupation or the other. The high proportions of civil servants, who are mostly low income and peasants farmers, are responsible for organic waste which is a typical characteristic of low income society. Income level plays a vital role in solid waste generation vis-a-vis its evacuation. In Nigeria, civil servants on GL 01- 05 are referred as low income, whose monthly earnings ranges between $\$ 5000.00$ to $15,000.00,33.7 \%$ of the respondents are within this category. Only $5.8 \%$ fit into the high-income group with monthly income of $\$ 45,000.00$ and above. See table 4.5 below and figure 4.5 . 
Table 3 Level of Income of Respondents

\begin{tabular}{lllll}
\hline Wards & Medium & Low & No Income \\
\hline & 45100 and above & $15100-45000$ & Below 15000 & \\
Old G R A & 49.9 & 30.3 & 7.4 & 12.8 \\
New G R A & 44.3 & 31.2 & 10.4 & 14.1 \\
F/Mada & 37.4 & 26.5 & 11.4 & 24.3 \\
Yelwa & 40.2 & 30.3 & 10.0 & 19.5 \\
Dan Iya & 41.4 & 30.4 & 6.4 & 21.8 \\
Makama & 33.6 & 26.8 & 8.3 & 31.3 \\
Ibrahim Bako & 28.6 & 16.7 & 4.1 & 50.9 \\
Nassarawa & 22.1 & 12.4 & 4.2 & 63.3 \\
Dan Kade & 20.5 & 4.6 & 2.4 & 72.5 \\
Dawaki & 15.9 & 3.9 & 1.8 & 78.4 \\
Dan Amar & 14.9 & 9.4 & 1.2 & 74.5 \\
Hardo & 25.4 & 12.5 & 1.5 & 60.6 \\
\hline Average & $\mathbf{3 3 . 6}$ & $\mathbf{1 9 . 4}$ & $\mathbf{5 . 8}$ & $\mathbf{4 1 . 2}$ \\
\hline
\end{tabular}

\section{Volume of Solid Waste Generated In Bauchi Metropolitan Area}

Turaki, (1982) reported that, residential area in Bauchi metropolis; generate an average volume of $0.003 \mathrm{~m}^{3} /$ person/day for high density areas, $0.005 \mathrm{~m}^{3} /$ person/day for high Density areas. On the other hand, Maikano, (2000) observed that in Bauchi metropolis; high-density residential areas generated an average volume of $0.007 \mathrm{~m}^{3} /$ person/day, medium-density areas generated $0.006 \mathrm{~m}^{3}$ person/day while low-density areas $0.009 \mathrm{~m}^{3} /$ person/day. In the two studies, no account of weight of solid wastes generated was considered and the second researcher, Maikano, claimed that residential density was not a strong factor in determining the quantities of solid wastes generation as asserted by the first researcher.

In another development a World Bank sponsored project, World Bank, (1998) adopted weight as the standard measure for determining amount of solid wastes quantities. For instance data for thirty countries compiled by the World Bank showed that per capita wastes generation ranged between 0.6 and $1.5 \mathrm{~kg} / \mathrm{capita} / \mathrm{day}$ for low income countries and 0.8 and $2.0 \mathrm{~kg} / \mathrm{capita} / \mathrm{day}$ for industrialized countries. For Nigeria, the average per capita waste generation stood at $1.02 \mathrm{~kg} /$ person/day. The maximum figure was $1.2 \mathrm{~kg} / \mathrm{capita} /$ day recorded in Port Harcourt while the lowest figure was $1.2 \mathrm{~kg} / \mathrm{capita} /$ day recorded in Minna.

Bauchi metropolis is not one of the high waste generators among Nigerian urban centres. This study discovered that the average solid waste generation for low income earners was $0.0033 \mathrm{~m}^{3} / \mathrm{capita} / \mathrm{day}$, $0.0040 \mathrm{~m}^{3} / \mathrm{capita} /$ day for medium income earners and 0.0046 for high income areas. The overall average stood at $0.004 \mathrm{~m}^{3} /$ capita/day as in the table below;

Table 4 Per Capita Solid Waste Generation In Volumes in $\mathrm{m}^{3}$

\begin{tabular}{|c|c|c|c|c|c|c|c|c|}
\hline Ward & Density & Garbage & Rubbish & Trash & Ash & Polythene & Total & Average \\
\hline Old GRA & Low & 0.0111 & 0.0057 & 0.0048 & 0.0010 & 0.0053 & 0.0297 & 0.0047 \\
\hline New GA & Low & 0.0092 & 0.0061 & 0.0052 & 0.0008 & 0.0047 & 0.0260 & 0.0043 \\
\hline $\bar{F} / \mathrm{Mada}$ & Low & $0.0100^{-}$ & 0.0067 & 0.0060 & 0.0012 & 0.0060 & 0.0299 & 0.0050 \\
\hline Yelwa & Medium & $0.0100^{\circ}$ & 0.0060 & 0.0041 & 0.0041 & 0.0040 & 0.0282 & 0.0047 \\
\hline Dan Iya & Medium & 0.0072 & 0.0059 & 0.0052 & 0.0034 & 0.0054 & 0.0271 & 0.0045 \\
\hline Makama & Medium & 0.0052 & 0.0062 & 0.0048 & 0.0037 & 0.0049 & 0.0248 & 0.0041 \\
\hline I/ Bako & Medium & 0.0070 & 0.0049 & 0.0050 & $0.002 \overline{4}$ & 0.0046 & 0.0239 & 0.0040 \\
\hline Nassarawa & $\mathrm{High}$ & 0.0039 & 0.0047 & 0.0051 & 0.0043 & 0.0035 & 0.0215 & $0.003 \overline{6}$ \\
\hline Dan Kade & High & 0.0033 & 0.0050 & $0.004 \overline{5}$ & 0.0051 & 0.0038 & 0.0217 & 0.0036 \\
\hline Dawaki & High & 0.0041 & 0.0032 & 0.0047 & 0.0038 & 0.0028 & 0.0186 & 0.0031 \\
\hline Dan Amar & High & 0.0037 & 0.0028 & 0.0037 & 0.0051 & 0.0026 & 0.0179 & 0.0030 \\
\hline Hardo & Figh & 0.0040 & 0.0037 & 0.0044 & 0.0041 & 0.0038 & 0.0200 & 0.0033 \\
\hline Total & & 0.0787 & 0.0609 & 0.0575 & 0.0390 & 0.0514 & 0.2875 & \\
\hline Average & & 0.0066 & 0.0051 & 0.0048 & 0.0033 & 0.0049 & & \\
\hline
\end{tabular}

The volume of solid wastes general in Bauchi metropolis is relatively small because of the low income, but ineffective evacuative was the major factor responsible for accumulation of solid wastes in the metropolis.

\section{Quantity of Solid Waste Generated In Bauchi Metropolis}

Quantitatively, the amount of solid waste generated in Bauchi metropolis is $0.16 \mathrm{~kg}$ lower than the national average per capita. The average solid waste generated in high density residential areas at 0.79 $\mathrm{kg} /$ capita/day; $0.89 \mathrm{~kg} / \mathrm{capita} /$ day for medium density residential areas and $1.03 \mathrm{~kg} / \mathrm{capita} /$ day low-density residential areas. The general average per capital solid waste generated was $0.86 \mathrm{~kg} / \mathrm{capita} / \mathrm{day}$ as in the table below; 
Table 5 Per Capita Solid Waste Generation In Volumes

\begin{tabular}{|c|c|c|c|c|c|c|c|c|}
\hline Ward & Density & Garbage & Rubbish & Trash & Ash & Polythene & Total & Average \\
\hline Old G R A & Low & 1.12 & 0.99 & 1.00 & 0.45 & 1.57 & 5.13 & 1.03 \\
\hline New GRA & Low & 1.28 & $0.90^{\circ}$ & 1.10 & 0.30 & 1.44 & 5.02 & 1.00 \\
\hline $\mathrm{F} / \mathrm{Mada}$ & Low & 1.02 & 1.11 & $0.80^{\circ}$ & 0.65 & 1.31 & 4.89 & 0.98 \\
\hline Yelwa & Medium & 0.86 & $0.91^{-}$ & 1.03 & 0.77 & 0.99 & 4.56 & 0.91 \\
\hline Dan Iya & Medium & 0.76 & $0.83^{-}$ & 0.91 & 0.64 & 0.87 & 4.01 & $0.80^{-}$ \\
\hline Makama & Medium & 0.62 & 0.58 & 0.75 & 1.08 & 1.00 & 4.03 & $0.8 \overline{1}^{-}$ \\
\hline I Bako & Medium & 0.80 & $0.92^{-}$ & 0.78 & 0.87 & 1.04 & 4.41 & 0.88 \\
\hline Aasearawa & High & 0.37 & 0.75 & 0.50 & 1.34 & 0.54 & 3.50 & 0.70 \\
\hline Dan Kade & High & 0.52 & 0.67 & 0.71 & $1.54^{-}$ & $0.80^{\circ}$ & 4.24 & 0.85 \\
\hline Dawaki & $\mathrm{High}$ & $0.41^{-}$ & 0.82 & 0.49 & $1.6 \overline{6}$ & $0.6 \overline{1}^{-}$ & 3.99 & 0.80 \\
\hline Dan Amar & $\mathrm{High}$ & 0.52 & 0.54 & 0.62 & $1.47^{-}$ & 0.48 & 3.49 & 0.70 \\
\hline Hardo & High & $0.6 \overline{1}^{-}$ & 0.47 & $0.5 \overline{1}$ & 1.21 & 0.69 & 3.49 & 0.70 \\
\hline Total & & 8.75 & 9.49 & $9.20^{-}$ & 12.0 & 11.31 & 50.74 & \\
\hline Average & & 0.73 & 0.79 & 0.77 & 1.00 & 0.95 & & \\
\hline
\end{tabular}

\section{Income and quantity of solid waste}

Income level play vital role in the quantity and composition of solid waste generation. Through this research, it is discovered that personal income has been found to have the most significant effect on waste generation due to its impact on individual consumption pattern. It has been noted that the rate of solid waste generation per capita increases as the income level of the household increases as shown in the figure below;

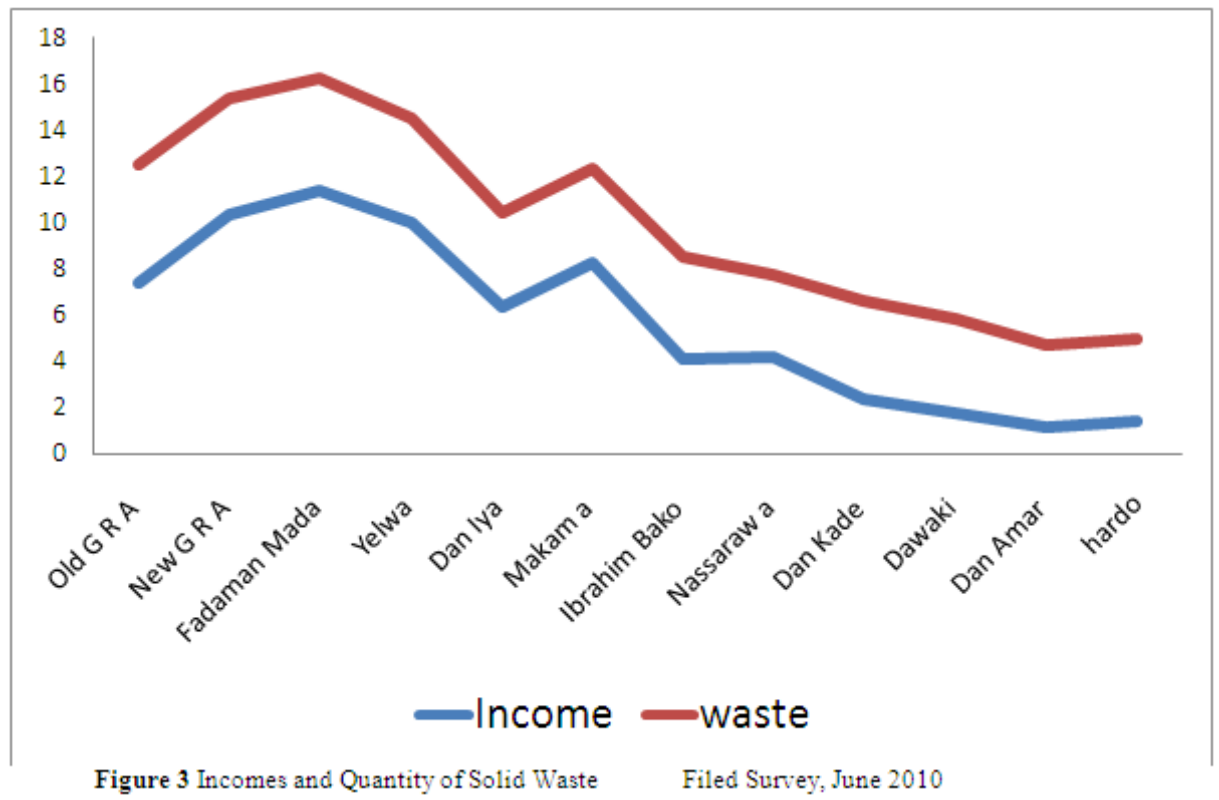

Rise income do not only increase the quantity of household waste generated, high income earners also generate more of non- biodegradable solid waste than the low income.

In this study it appears relationship exist between income level and quantity of solid waste generation, The rank correlation

$$
\begin{aligned}
& \mathrm{r}=\mathrm{N} \sum \mathrm{XY}-\left(\sum \mathrm{X}\right)\left(\sum \mathrm{Y}\right) \\
& {\left[\left(\mathrm{N} \sum \mathrm{X}^{2}\right)-\left(\sum \mathrm{X}\right)^{2}\right]\left[\left(\mathrm{N} \sum \mathrm{Y}^{2}\right)-\left(\sum \mathrm{Y}\right)^{2}\right]}
\end{aligned}
$$

would be used to test the degree of association between them for the purpose of accepting or rejecting the null hypotheses.

\section{Hypothesis}

- HO: There is no significant relationship between income level and the quantity of solid waste generation

- H1: There is a significant relationship between income level and the quantity of solid waste generation 
The rank correlation (r) model is used to test the strength of the relationship as follows:

$\mathrm{r}=\mathrm{N} \sum \mathrm{XY}-\left(\sum \mathrm{X}\right)\left(\sum \mathrm{Y}\right)$

\begin{tabular}{|c|c|c|c|c|c|}
\hline Wards & $\mathrm{X}$ & $\mathrm{Y}$ & $\mathrm{X}^{2}$ & $\mathrm{Y}^{2}$ & $\mathrm{XY}$ \\
\hline $\mathrm{A}$ & 44.9 & 0.279 & 2016.01 & 0.088 & 14.820 \\
\hline B & 44.3 & 0.260 & 1962.49 & 0.068 & 11.518 \\
\hline $\mathrm{C}$ & 37.4 & 0.299 & 1398.76 & 0.089 & 11.183 \\
\hline $\mathrm{D}$ & 40.2 & 0.282 & 1616.04 & 0.080 & 11.336 \\
\hline$E$ & 41.1 & 0.271 & 1689.21 & 0.073 & 11.138 \\
\hline $\mathrm{F}$ & 33.6 & 0.248 & 1128.96 & 0.062 & 8.333 \\
\hline $\mathrm{G}$ & 28.6 & 0.239 & 819.96 & 0.057 & 6.834 \\
\hline $\mathrm{H}$ & 22.1 & 0.215 & 488.41 & 0.046 & 4.752 \\
\hline $\mathrm{I}$ & 20.5 & 0.211 & 420.25 & 0.045 & 4.326 \\
\hline $\mathrm{J}$ & 15.9 & 0.186 & 252.81 & 0.035 & 2.957 \\
\hline $\mathrm{K}$ & 14.9 & 0.179 & 222.01 & 0.032 & 2.667 \\
\hline $\mathrm{L}$ & 22.4 & 0.200 & 501.76 & 0.040 & 4.480 \\
\hline TOTAL & 369.9 & 2.887 & 12516.67 & 0.716 & 94.344 \\
\hline
\end{tabular}

$\sum X=369.9$

$\sum \mathrm{Y}=2.887$

$\sum X^{2}=12516.67$

$\sum Y^{2}=0.716$

$\sum X Y=94.344$

$\mathrm{r}=$

$12 \times 94.344-369.9 \times 2.887$

$[(12 \times 12516.67)-(136836.01)] X[(12 \times 0.716)-(8.335)]$

67.227

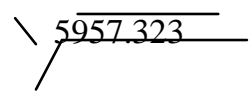

$=$

67.227

77.184

$\mathrm{r} \quad=$

$\underline{0.871}$

The result of hypothesis I shows that the calculated value of $r$ is 0.871 . This indicates that there is high positive correlation between the two variables, therefore. The null hypothesis that says there is no significant relationship between income level and the quantity of solid waste generation in Bauchi metropolitan area is rejected, thus accepting the alternative hypothesis $(\mathrm{H} 1)$.

\section{Recommendation}

There are three global options for dealing with waste. The first option is to collect the waste and transport it to a legal and well- protected dumpsite, where it can be disposed off. In this case waste remains as waste. The second option is to re-use waste, or recycle it. This includes composting of any waste that can rot. In this option waste becomes something useful again, as was already explained earlier in this session. The third option is the treatment of waste. This includes controlled burning and controlled burying of waste. In this case waste can become a source of useful energy for example in the form of heat or gas for cooking.

Solid waste management services form the core of municipal services and cannot be sustained without community cooperation and participation in all operations. The designed system should be user friendly and sustainable. To this end, efforts are needed to assess the economic profiles of each community it determines the quantity and the composition of their solid waste. The understanding of the economic characteristics of communities within the local authorities' operational area is vital for the delivery of accessible, affordable, relevant, acceptable and effective services. Socio-economic factors are significant in Bauchi metropolis as in any other traditional city in a developing country with heterogeneous communities. The strategies used in solid waste management in Bauchi metropolis were appraised with a view to identifying their strength and 
weaknesses. There has been failure to take cognizance of the crucial and important roles of economic status in the solid waste management in Bauchi metropolis. This is a major explanation for the lack of efficiency and productivity of the waste management system in Bauchi metropolis. The roles of income are to be identified and integrated in the solid waste management strategies with a view to achieving a clean and healthy living environment in Bauchi metropolis

\section{References}

[1]. Abel, O.A (2009). An Analysis of Solid Waste Generation in a Traditional African City: The Example of Ogbomoso, Nigeria Environment and Urbanization, SAGE Journals, 19(2): 527-537.

[2]. Adedibu, A.A., (1999) 'A Comparative Analysisof Solid Waste Generation and Composition in Ilorin and Offa, Kwara State. Paper Presented at the National Conference on Development and Environment Organised By N I S E R University Of Ibadan From $22^{\text {nd }}-$ $25^{\text {th }}$ March 1999

[3]. Agunwamba, J. C., (1998). Analysis of scavengers' activities and recycling in some cities of Nigeria. Environmental Management, 32 (1): 116-127.

[4]. Alkali, J.L.S. (2005), Planning Sustainable Urban Growth in Nigeria: Challenges and Strategies. Paper Presented at Conference on Planning Sustainable Urban Growth and Sustainable Architecture, Held at The ECOSOC Chambers, United Nations Headquarters, New York On $6^{\text {th }}$ June 2005.

[5]. Bogoro A. G. (2010) Management of Solid Waste at Household Level 'Environmental Watch' Journal of School of Environmental Studies. Vol., 5, No. 1, September 2010, Pp.64-70. The Federal Polytechnic, Bida,

[6]. Cointreau, S. J., (1982). Environmental Management of Urban Solid Waste in Developing Countries: A Project Guide. Urban Development Technical Paper No 5. The World Bank, Washington, DC. June.

[7]. Dauda, M., And Osita, O.O.,(2003). Solid Waste Management and Reuse in Maiduguri, Nigeria. 29th WEDC International Conference towards the Millennium Development Goal, Abuja.

[8]. Miller G. T.(1990), Living in the Environment: An Introduction to Environmental Science. Wadsworth Publishing Company, Belmont, California

[9]. Miranda, M.L., S.D. Bauer, and J.E. Aldy, (1996). Unit Pricing Programs for Residential Municipal Solid Waste: An Assessment of the Literatures. Report Prepared For U.S. Environmental Protection Agency, Washington D.C.

[10]. Miranda, M.L., J.W. Everett, D. Blume, and B.A. Roy, (1994). Marketbased Incentives and Residential Municipal Solid Waste. Journal of Policy Analysis and Management, 13(4), Pp. 681-698.

[11]. Ogwueleka, T.C., (2003). Analysis of Urban Solid Waste in Nsukka, Nigeria. Journal of Solid Waste Technology and Management, 29 (4): 239-246.

[12]. Repetto, R.; R.C. Dower; R. Jenkins; and J. Geoghegan. (1992). Pay-by-the-Bag Household Collection Charges to Municipal Solid Waste. Resources for the Future, Inc. November.

[13]. Reschovsky, J.D.and S.E. Stone. (1994). Market Incentives to Encourage Household Waste Recycling: Paying for What You Throw Away. Journal of Policy Analysis and Management. 13:1:120-139.

[14]. UN-Habitat (2006), State Of World's Cities 206/07: The Millennium Development Goals And Urban Sustainability; 30 Years Of Shaping The Habitat Agenda, Earthscan.

[15]. UNHCS-UN-Habitat (2003:140) The Challenges Of Slums: Global Report On Human Settlements 2003, Earthscan.

[16]. World Bank, (2001). Urban Environmental Priorities. Draft for Discussion, C.R. Bartone,

[17]. Urban Development Division, Infrastructure Group, Washington, D.C., January.

[18]. World Bank, (2012). World Development Report, Development and Environment, New York. Paper No 13. 